\title{
Structural stability of $\mathrm{CuAl}_{2} \mathrm{O}_{4}$ under pressure
}

\author{
P A Agzamova ${ }^{1,2}$, A A Belik ${ }^{3}$ and S V Streltsov ${ }^{1,2}$ \\ ${ }^{1}$ M.N. Miheev Institute of Metal Physics of Ural Branch of Russian Academy of Sciences, 620108 Ekaterinburg, Russia \\ ${ }^{2}$ Ural Federal University, Mira St. 19, 620002 Ekaterinburg, Russia \\ ${ }^{3}$ International Center for Materials Nanoarchitectonics (WPI-MANA), National Institute for Materials \\ Science (NIMS), Namiki 1-1, Tsukuba, Ibaraki, 305-0044, Japan
}

E-mail: polly@imp.uran.ru

Received xxxxxx

Accepted for publication $\mathrm{xxxxxx}$

Published xxxxxx

\begin{abstract}
Structural properties of $\mathrm{CuAl}_{2} \mathrm{O}_{4}$, which was recently argued to show unusual suppression of the Jahn-Teller distortions by the spin-orbit coupling, are investigated under pressures up to 6 $\mathrm{GPa}$. Analysis of X-ray powder diffraction experiments shows that $\mathrm{CuAl}_{2} \mathrm{O}_{4}$ gets unstable and decomposes onto $\mathrm{CuO}$ and $\mathrm{Al}_{2} \mathrm{O}_{3}$ at pressures $\sim 6 \mathrm{GPa}$ and temperature $\sim 1000 \mathrm{~K}$. This finding is complemented by the DFT $+\mathrm{U}+\mathrm{SOC}$ calculations, which demonstrate that this instability is partially driven by a (relatively) large compressibility of strongly Jahn-Teller distorted CuO.
\end{abstract}

Keywords: spinels, spin-orbit-coupling

\section{Introduction}

The $A B_{2} \mathrm{O}_{4}(A$ - divalent cation such as $\mathrm{Cu}, \mathrm{Co} ; B$-trivalent cation, e.g., Al, Fe) family of spinel oxides is known for their unique physical properties, which have been attracting considerable attention over the years. There are multiferroics among them, e.g., $\mathrm{CdV}_{2} \mathrm{O}_{4}$ [1], $\mathrm{CoCr}_{2} \mathrm{O}_{4}$ [2], and $\mathrm{FeCr}_{2} \mathrm{O}_{4}$ [3, 4], materials with charge [5] and orbital ordering [6], some of these spinels show rather unusual distortions of the crystal structure, which can be accompanied by strong modifications of their magnetic properties and even openning the spin gap [7-9].

In fact two different sites are available for metals in spinels: octahedral and tetrahedral. In "normal" spinels $-A(B)_{2} \mathrm{O}_{4}-B$ ions sit at octahedral positions, while in "inverse" ones $B(A B) O_{4}$ - they are distributed equaly between octahedral and tetrahedral voids (and of course an intermediate situation with random destribution is also possible). The transition metals (TM) can occupy both sites. While a lot of affords are now concentrated on studying the spinels with TMs having octahedral coordination, an opposite situation is equally interesting. In the present paper we study structural properties of $\mathrm{CuAl}_{2} \mathrm{O}_{4}$, where $\mathrm{Cu}^{2+}$ ions preferably occupy tetrahedral sites. They have $3 d^{9}$ electronic configuration and in tetrahedral surrounding $\mathrm{Cu} 3 d$ orbitals are split onto three high-lying $t_{2 g}$ levels separated from two low-lying $e_{g}$-levels. Therefore, there is one hole in the $t_{2 g}$ manifold in $\mathrm{CuAl}_{2} \mathrm{O}_{4}$, which is susceptible to further Jahn-Teller distortions to lower the total energy. However, previous X-ray powder diffraction studies did not detect any indications of the Jahn-Teller effect in $\mathrm{CuAl}_{2} \mathrm{O}_{4}$ [10]. It was later shown theoretically that the absence of the Jahn-Teller distortions can be related with formation of the $j_{\text {eff }}=1 / 2$ state $[11,12]$. Thus, it was suggested that $\mathrm{Cu}^{2+}$ ions behave in this material similar to $\operatorname{Ir}^{4+}$ ions also having $t_{2 g}{ }^{5}$ electronic configuration. Strong spin-orbit splitting lifts degeneracy and puts a single hole onto the $j_{\text {eff }}=1 / 2$ spin-orbital retaining only Kramers degeneracy, which can not be removed by the Jahn-Teller distortions, see e.g. [13]. Moreover, it was shown that suppression of the Jahn-Teller effect is not gradual, but there is a critical value of strength of the spin-orbit coupling above which distortions vanish $[14,15]$.

Possible stabilization of the $j_{\text {eff }}=1 / 2$ state makes $\mathrm{CuAl}_{2} \mathrm{O}_{4}$ a unique system, which is similar to famous iridates [16, 17], but based on the $3 d$ transition metal $\mathrm{Cu}$. First theoretical calculations indeed demostrated that one might expect strong anisotropy of the exchange coupling and stressed importance of the frustration effects, since magnetic $\mathrm{Cu}^{2+}$ ions form strongly frustrated diamond lattice [11]. 
However, all these results are based on, first, the assumption that there is an ideal ordering of $\mathrm{Cu}^{2+}$ ions and they occupy only tetrahedral sites (i.e. this is normal spinel), while there are experimental evidences of antisite defects $[10,18]$. Second, there is of course always competition between the Jahn-Teller effect and spin-orbit coupling and, e.g., theoretical calculations show that applying pressure one may shift the balance between these two factors and $\mathrm{CuAl}_{2} \mathrm{O}_{4}$ is expected to show Jahn-Teller distortions already at pressure [12]. Third, because of antisite disorder observed in previous studies it is highly desirable to find alternative synthesis methods or ways, which would modify the distribution of $\mathrm{Cu}^{2+}$ cations between the tetrahedral and octahedral sites of the spinel structure. The high-pressure high-temperature annealing is one of such methods.

In this work we focused on experimental and theoretical investigations of structural properties of $\mathrm{CuAl}_{2} \mathrm{O}_{4}$ under high pressure. Ex-situ X-ray powder diffraction studies showed that at temperatures above about $1070 \mathrm{~K}$ and pressure of $6 \mathrm{GPa}$ $\mathrm{CuAl}_{2} \mathrm{O}_{4}$ decomposes through a complex way to a final mixture of initial oxides $\mathrm{CuO}$ and $\mathrm{Al}_{2} \mathrm{O}_{3}$. The DFT+U+SOC calculations confirmed that $\mathrm{CuAl}_{2} \mathrm{O}_{4}$ is unstable at high pressure.

\section{Experimental details and results}

$\mathrm{CuAl}_{2} \mathrm{O}_{4}$ was prepared from a stoichiometric mixture of $\mathrm{Al}_{2} \mathrm{O}_{3}(99.9 \%)$ and $\mathrm{CuO}(99.9 \%)$. The mixture was pressed into a pellet and annealed on Pt foil at $1193 \mathrm{~K}$ for $84 \mathrm{~h}$ and at $1293 \mathrm{~K}$ for $38 \mathrm{~h}$ in air with several intermediate grindings. This phase will be called ambient-pressure (AP) $\mathrm{CuAl}_{2} \mathrm{O}_{4}$, and it had orange-brown color. As-prepared single-phase $\mathrm{CuAl}_{2} \mathrm{O}_{4}$ was then annealed in $\mathrm{Au}$ capsules at $6 \mathrm{GPa}$ and different temperatures for $2 \mathrm{~h}$ using a belt-type high-pressure apparatus (where the annealing temperature was reached in 10-15 min). After the high-pressure high-temperature treatments, the samples were quenched to room temperature (RT) by turning off current, and the pressure was slowly released. Such samples will be called high-pressure (HP) samples. We emphasize that the melting point of $\mathrm{Au}$ is above about $1600 \mathrm{~K}$ at $6 \mathrm{GPa}[19]$; therefore, the high-pressure annealing could be performed safely up to $1523 \mathrm{~K}$ in gold capsules.

X-ray powder diffraction (XRPD) data were collected at RT on a RIGAKU MiniFlex600 diffractometer using $\mathrm{CuK} \alpha$ radiation ( $2 \theta$ range of $8-140^{\circ}$, a step width of $0.02^{\circ}$, and a scan speed of $1 \mathrm{deg} / \mathrm{min})$. XRPD data were analysed by the Rietveld method using RIETAN-2000 [20].

$\mathrm{CuAl}_{2} \mathrm{O}_{4}$ prepared at ambient pressure was single-phase and had sharp reflections on XRPD patterns. The structural analysis gave the following cation distribution $\left[\mathrm{Cu} 0.676 \mathrm{Al}_{0.324}\right]_{8 a}\left[\mathrm{Al}_{1.676} \mathrm{Cu}_{0.324}\right]_{16 d} \mathrm{O}_{4}$. The similar distribution was found in the literature for samples prepared at ambient pressure (for example, $\left[\mathrm{Cu}_{0.68} \mathrm{Al}_{0.32}\right]_{8 a}\left[\mathrm{Al}_{1.68} \mathrm{Cu}_{0.32}\right]_{16 d} \mathrm{O}_{4}$ in [10] or $x=0.36-0.39$ for $\left[\mathrm{Cu}_{1-x} \mathrm{Al}_{x}\right]_{8 a}\left[\mathrm{Al}_{2-x} \mathrm{Cu}_{x}\right]_{16 d} \mathrm{O}_{4}$ in [18]).
XRPD patterns of the samples annealed at $6 \mathrm{GPa}$ and different temperatures are given on Figure 1. The spinel structure remains after annealing at $6 \mathrm{GPa}$ and $880 \mathrm{~K}$ (powdered sample had orange-brown color) or $1048 \mathrm{~K}$ (powdered sample had brown color).

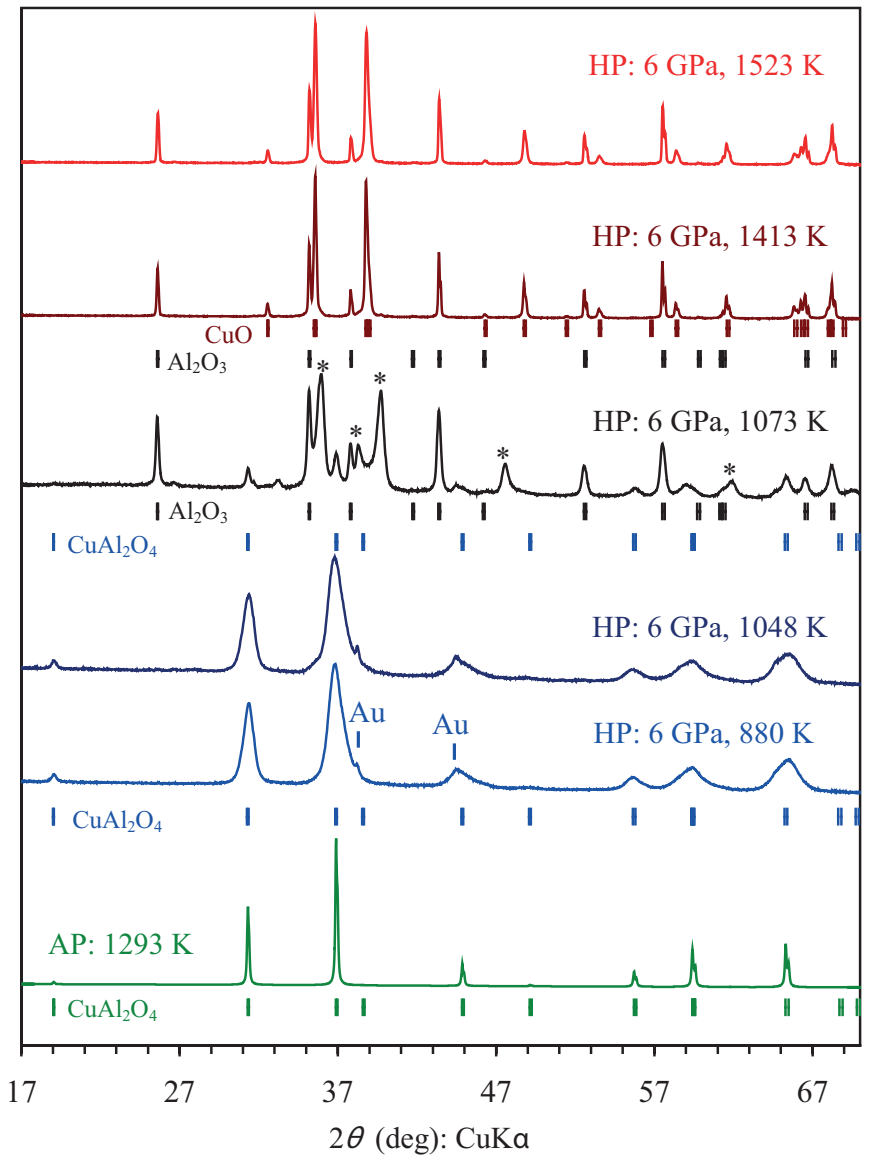

Figure 1. Experimental X-ray powder diffraction patterns of $\mathrm{CuAl}_{2} \mathrm{O}_{4}$ prepared at ambient pressure (bottom) and at $6 \mathrm{GPa}$ and different temperatures (annealing conditions are given on the figure). Possible Bragg reflections for the given phases are shown by tick marks. Stars mark the strongest unidentified reflections.

However, the reflections of the spinel phase were significantly broadened, and additional reflections from $\mathrm{Au}$ (the capsule material) appeared. Particle size is unlikely to significantly decrease at such annealing conditions. Therefore, the broadening of the reflections could originate from the accumulation of huge stress. The appearance of Au could be caused by a small and gradual loss of oxygen or copper by $\mathrm{CuAl}_{2} \mathrm{O}_{4}$ near contacts with $\mathrm{Au}$, where oxygen or metallic copper attacks Au and demages the capsule material.

An increase of the annealing temperature to $1073 \mathrm{~K}$ (at 6 $\mathrm{GPa}$ ) resulted in a partial decomposition: an XRPD pattern showed the presence of a spinel phase, $\mathrm{Al}_{2} \mathrm{O}_{3}$, and reflections from unknown phase(s) (see figure 2). This powdered sample had black color, and the pellet looked like a solidified melt. Further increase of the annealing temperature to $1413 \mathrm{~K}$ or 
$1523 \mathrm{~K}$ resulted in the complete decomposition of $\mathrm{CuAl}_{2} \mathrm{O}_{4}$ to a mixture of initial oxides $\left(\mathrm{Al}_{2} \mathrm{O}_{3}\right.$ and $\left.\mathrm{CuO}\right)$ with sharp reflections and these samples had black color. Note that no reflections from $\mathrm{Au}$ were observed in these cases probably because the sample was heated relatively fast above the decomposition temperature, and $\mathrm{CuO}$ (and $\mathrm{Al}_{2} \mathrm{O}_{3}$ ) does not attack $\mathrm{Au}$ at the annealing conditions.

It is known that at ambient pressure, $\mathrm{CuAl}_{2} \mathrm{O}_{4}$ decomposes to a mixture of $\mathrm{Al}_{2} \mathrm{O}_{3}$ and $\mathrm{CuAlO}_{2}$ above about $1470 \mathrm{~K}$ with the loss of oxygen [21]. The application of the high pressure prevents the loss of oxygen, as can be seen from the presence of $\mathrm{CuO}$ instead of $\mathrm{Cu}_{2} \mathrm{O}$, but decreases the decomposition temperature of $\mathrm{CuAl}_{2} \mathrm{O}_{4}$ from about $1470 \mathrm{~K}$ at ambient pressure to about $1070 \mathrm{~K}$ at $6 \mathrm{GPa}$.

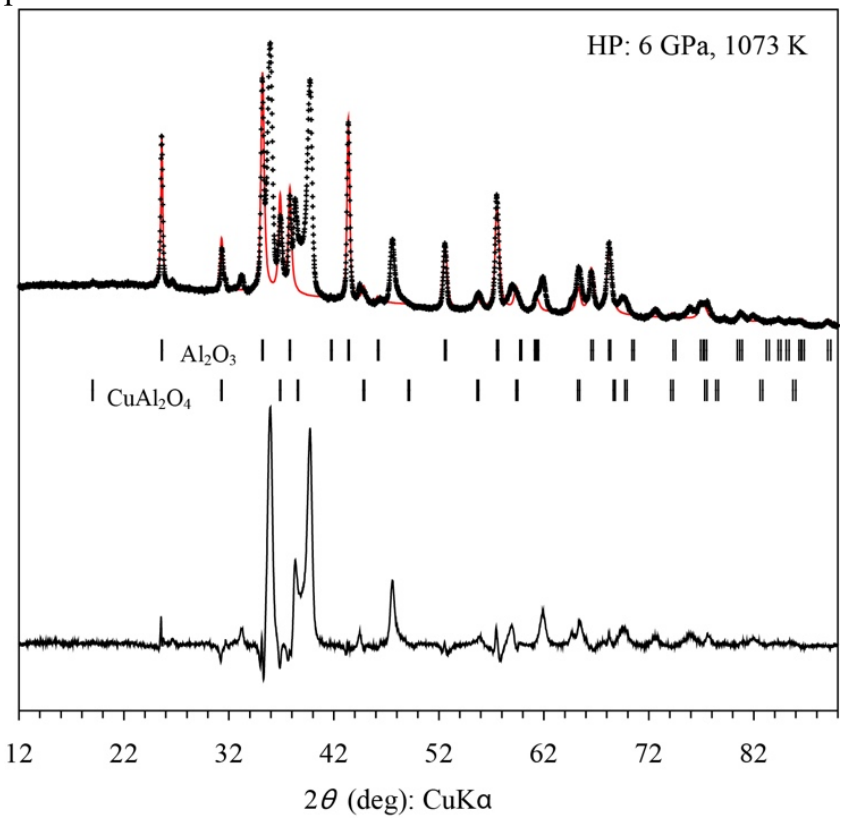

Figure 2. Experimental (crosses), calculated (red line), and difference X-ray powder diffraction patterns for $\mathrm{CuAl}_{2} \mathrm{O}_{4}$ annealed at $6 \mathrm{GPa}$ and $1073 \mathrm{~K}$. Possible Bragg reflections for $\mathrm{Al}_{2} \mathrm{O}_{3}$ and $\mathrm{CuAl}_{2} \mathrm{O}_{4}$ phases are shown by tick marks. The difference pattern emphasizes reflections from new phase(s).

\section{Computational methods}

First-principles density-functional theory (DFT) calculations were conducted to investigate the stability of $\mathrm{CuAl}_{2} \mathrm{O}_{4}$ under pressure.

The calculations of $\mathrm{CuAl}_{2} \mathrm{O}_{4}, \mathrm{CuO}$, and $\mathrm{Al}_{2} \mathrm{O}_{3}$ compounds were carried out using the Vienna $\mathrm{Ab}$ initio Simulation Package (VASP) [22]. We utilized the projector augmentedwave (PAW) method [23] with the Perdew-Burke-Ernzerhof (PBE) type of exchange-correlation functional [24] within the general gradient approximation $(\mathrm{GGA}+\mathrm{U})$ [25]. Initial crystal structure parameters were taken for $\mathrm{CuAl}_{2} \mathrm{O}_{4}$ from [10] ( $T=40$ $K)$, for $\mathrm{CuO}$ from [26] $(T=293 \mathrm{~K})$ and for $\mathrm{Al}_{2} \mathrm{O}_{3}$ from [27]. They were relaxed for all calculated volumes. On site Coulomb repulsion parameter $U$ was chosen to be $9 \mathrm{eV}$, while intra-atomic Hund's exchnage $1 \mathrm{eV}$ [12]. The cut-off energy was taken to be $E_{\text {cutoff }}=560 \mathrm{eV}$ and $6 \times 6 \times 6$ Monkhorst-Pack grid of $k$-points was used during calculations. The spin-orbit coupling (SOC) was included to the calculation scheme for $\mathrm{CuAl}_{2} \mathrm{O}_{4}$ and $\mathrm{CuO}$.

Strictly speaking DFT is valid only for zero temperature, while majority of high-pressure experimental work is performed at $300 \mathrm{~K}$ and above. Therefore, we would like to mention that there is always at least the $300 \mathrm{~K}$ difference between theoretical and experimental conditions. This temperature difference is sometimes responsible for different values of pressure when a phase transition is predicted from first-principles calculations and observed in experiments.

\section{Theoretical study of structural stability}

The total energy dependence on the unit cell volume for $\mathrm{CuAl}_{2} \mathrm{O}_{4}, \mathrm{CuO}$, and $\mathrm{Al}_{2} \mathrm{O}_{3}$ was obtained by series of calculations, where it was varied between about $-10 \%$ and $+10 \%$.

First of all, we see that equlibrium volumes $\mathrm{V}_{0}$ obtained in our calculations are close to experimental ones, so that $\left(V_{0}-V_{0}^{\text {exp }}\right) / V_{0}^{\text {exp }}$ is 0.031 for $\mathrm{CuAl}_{2} \mathrm{O}_{4}$ [10], 0.008 for $\mathrm{CuO}$ [26] and 0.027 for $\mathrm{Al}_{2} \mathrm{O}_{3}$ [27], which are very typical estimates for DFT [28]. The energy-volume curves for $\mathrm{CuAl}_{2} \mathrm{O}_{4}, \mathrm{CuO}$, and $\mathrm{Al}_{2} \mathrm{O}_{3}$ compounds are given in Figure 3.

Next we extracted other parameters of the equation of state (the zero pressure total energy $E_{0}$, the equilibrium volume $V_{0}$, and the bulk modulus $\left(B_{0}\right)$ by fitting the calculated energies versus volume to the third order Birch-Murnaghan equation of states [29]. Already at this level we see that compressibility (inverse of Bulk modulus) of $\mathrm{CuO}$ is much larger than in both $\mathrm{CuAl}_{2} \mathrm{O}_{4}$ and $\mathrm{Al}_{2} \mathrm{O}_{3}$ (table 1).

Table 1. The equation of state parameters of $\mathrm{CuAl}_{2} \mathrm{O}_{4}, \mathrm{CuO}$, and $\mathrm{Al}_{2} \mathrm{O}_{3}$ obtained by fitting the calculated $\mathrm{GGA}+\mathrm{U}+\mathrm{SOC}$ energies versus volume data to the third order Birch-Murnaghan equation of states.

\begin{tabular}{lccc}
\hline & $\mathrm{CuAl}_{2} \mathrm{O}_{4}$ & $\mathrm{CuO}$ & $\mathrm{Al}_{2} \mathrm{O}_{3}$ \\
\hline$E_{0}, \mathrm{eV}$ & -90.8 & -31.2 & -224.5 \\
$V_{0}, \AA$ & 135.2 & 81.6 & 262.9 \\
$B_{0}, \mathrm{GPa}$ & 187.7 & 140.4 & 230.8 \\
$B_{0}$, & 4.2 & 4.7 & 4.04 \\
\hline
\end{tabular}

The thermodynamic stability of $\mathrm{CuAl}_{2} \mathrm{O}_{4}$ was investigated by comparing the enthalpies of $\mathrm{CuAl}_{2} \mathrm{O}_{4}$ and $\mathrm{CuO}+\mathrm{Al}_{2} \mathrm{O}_{3}$, which are shown in Figure 4. One may see that in DFT $+\mathrm{U}+\mathrm{SOC}$ calculations $\mathrm{CuAl}_{2} \mathrm{O}_{4}$ becomes unstable at pressures $\sim 8 \mathrm{GPa}$, which is close to experimental $P_{c}=6 \mathrm{GPa}$. 
It is instructive to study physical origin of this decomposition. For this in Table 2 we present results of fitting of enthalpy by the third order polynomials

$$
H(P)=a \cdot P^{2}+b \cdot P+\mathrm{c}+d \cdot P^{3}
$$

for $\mathrm{CuAl}_{2} \mathrm{O}_{4}, \mathrm{CuO}$, and $\mathrm{Al}_{2} \mathrm{O}_{3}$ compounds (here $P$ stands for pressure).
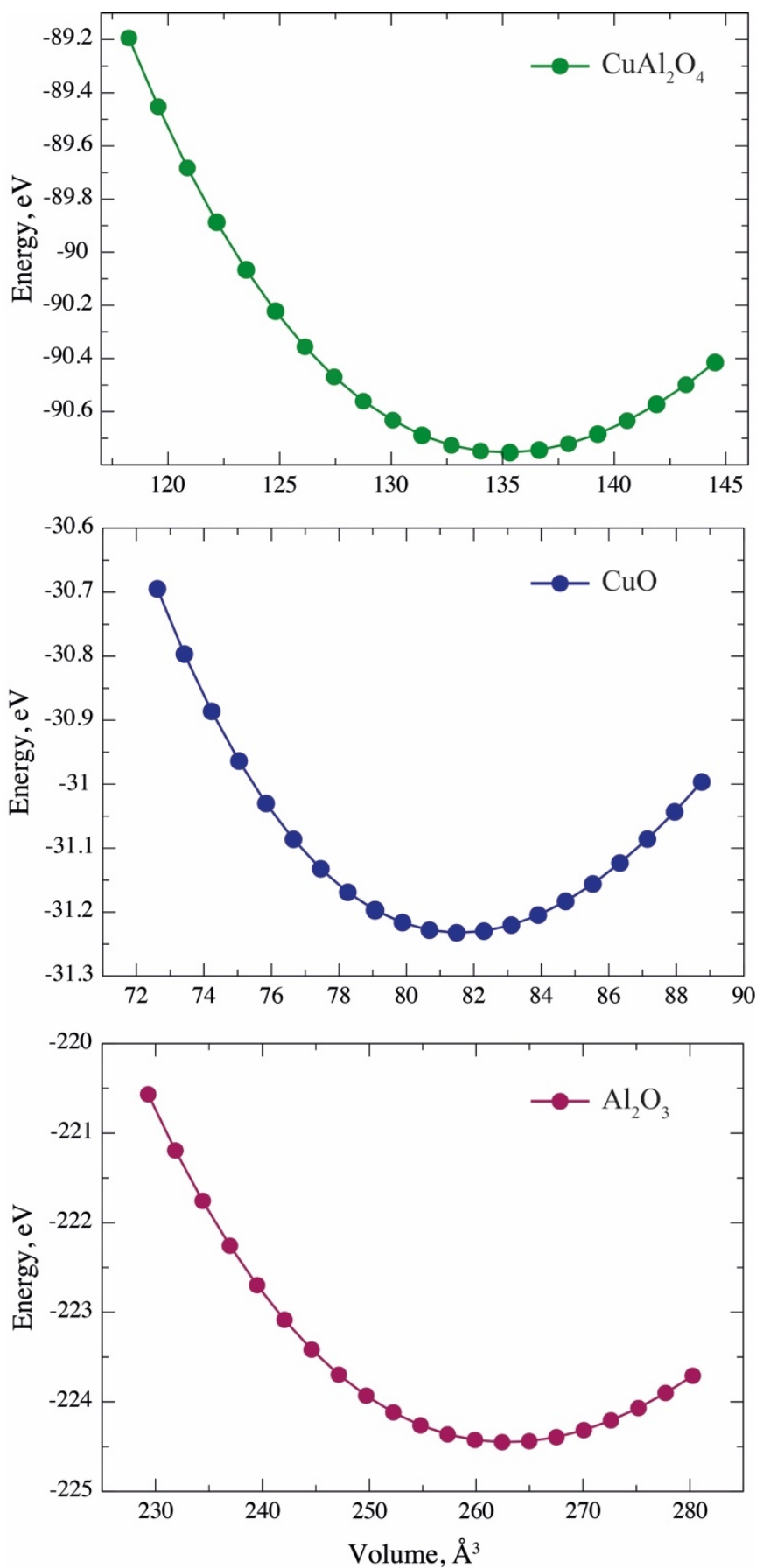

Figure 3. Energy-volume curves for $\mathrm{CuAl}_{2} \mathrm{O}_{4}, \mathrm{CuO}$, and $\mathrm{Al}_{2} \mathrm{O}_{3}$ obtained by fitting the third order Birch-Murnaghan equation of states to energy-volume data.
Table 2. Parameters of fitting GGA+U+SOC enthalpies by the third order polynomials $a \cdot P^{2}+b \cdot P+\mathrm{c}+d \cdot P^{3}$ for $\mathrm{CuAl}_{2} \mathrm{O} 4, \mathrm{CuO}$, and $\mathrm{Al}_{2} \mathrm{O}_{3}$. Here $P$ stands for pressure.

\begin{tabular}{|c|c|c|c|c|}
\hline & $a, \frac{e V}{(G P a)^{2}}$ & $b, \frac{e V}{G P a}$ & $c, e V$ & $d, \frac{e V}{(G P a)^{3}}$ \\
\hline $\mathrm{CuAl}_{2} \mathrm{O}_{4}$ & -0.001 & 0.422 & -45.378 & $6.723 \cdot 10^{-6}$ \\
\hline $\mathrm{CuO}$ & $\begin{array}{c}- \\
0.0005\end{array}$ & 0.127 & -7.808 & $4.547 \cdot 10^{-6}$ \\
\hline $\mathrm{Al}_{2} \mathrm{O}_{3}$ & $\begin{array}{c}- \\
0.0006\end{array}$ & 0.274 & -37.409 & $2.773 \cdot 10^{-6}$ \\
\hline
\end{tabular}

By analyzing parameters of fitting, one can see that quadratic and cubic terms, characterized by coefficients $a$ and $d$ respectively, are much smaller than other terms (parametrized by $b$ and $c$ ) and therefore these coefficients only weakly affect structural stability of the materials under consideration in a given pressure range.

One can see that the constant term $(c)$ is much smaller for $\mathrm{CuAl}_{2} \mathrm{O}_{4}$ and this reflects structural stability of this material at normal conditions.

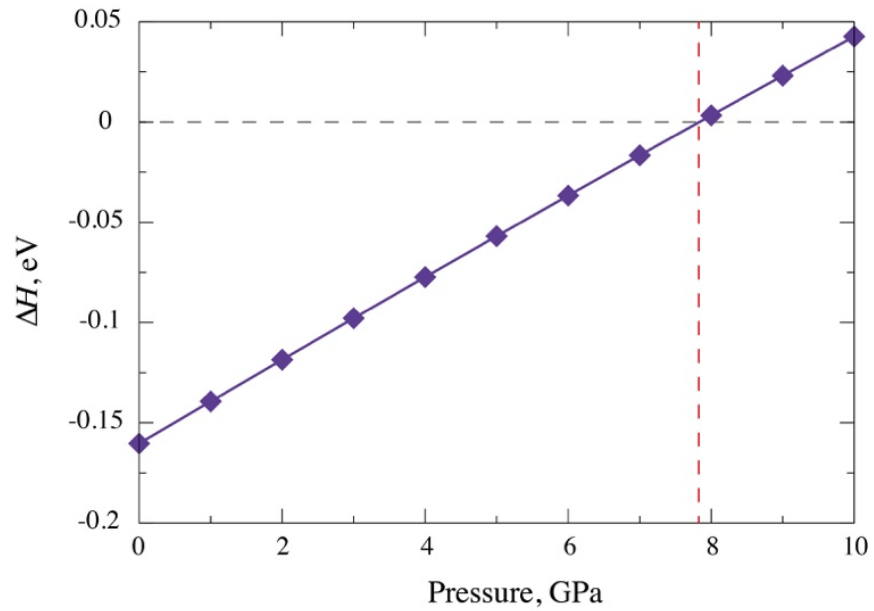

Figure 4. The calculated relative enthalpy $\Delta \mathrm{H}$ of $\mathrm{CuAl}_{2} \mathrm{O}_{4}$ with respect to $\left(\mathrm{CuO}+\mathrm{Al}_{2} \mathrm{O}_{3}\right)$ under various pressure conditions. One can see that $\mathrm{CuAl}_{2} \mathrm{O}_{4}$ is stable below $\sim 8 \mathrm{GPa}$.

The linear term, characterized by positive coefficient $b$, destabilizes all compounds, since the enthalpy grows in all of them due to this linear term. However, it increases very differently for $\mathrm{CuAl}_{2} \mathrm{O}_{4}, \mathrm{CuO}$, and $\mathrm{Al}_{2} \mathrm{O}_{3}$. If $b$ for mixture of $\mathrm{CuO}$ and $\mathrm{Al}_{2} \mathrm{O}_{3}$ would be larger than for $\mathrm{CuAl}_{2} \mathrm{O}_{4}$ then the later would be stable at any pressure. Our calculations show that this is not the case: $b_{C u A l 2 O 4}=0.422 \mathrm{eV} / \mathrm{GPa}$, while $b_{C u O+A l 2 O 3}$ $=0.403 \mathrm{eV} / \mathrm{GPa}$ and this is one of the reasons why $\mathrm{CuAl}_{2} \mathrm{O}_{4}$ decomposes under pressure. One can also see that $b$ coefficient for $\mathrm{CuO}$ is much smaller than for $\mathrm{Al}_{2} \mathrm{O}_{3}$ and therefore at pressures $\sim 8 \mathrm{GPa}$, the largest contribution to relative (with with respect to $\mathrm{CuAl}_{2} \mathrm{O}_{4}$ ) decrease of the enthalpy of the mixture $\mathrm{CuO}+\mathrm{Al}_{2} \mathrm{O}_{3}\left(\delta \mathrm{H}_{\mathrm{CuO}+\mathrm{Al2O}}=-3.54 \mathrm{eV}\right)$ is mostly due to $\mathrm{CuO}\left(\delta H_{C u O}=-2.36 \mathrm{eV}\right)$. Thus, small $b$ for $\mathrm{CuO}$ coefficient 
is one of the most important factors, which results in decomposition of $\mathrm{CuAl}_{2} \mathrm{O}_{4}$.

Interestingly, the compressibility of $\mathrm{CuO}$ has been studied experimentally in Ref. [26], where it was shown that it is very different for three different $\mathrm{Cu}-\mathrm{O}$ bonds.

The $\mathrm{Cu}^{2+}$ ions in this material have octahedral surrounding, but these octahedra are so elongated, that it even seems that $\mathrm{Cu}$ ions are in the middle of plaquetes, not octahedra, see Figure 6.
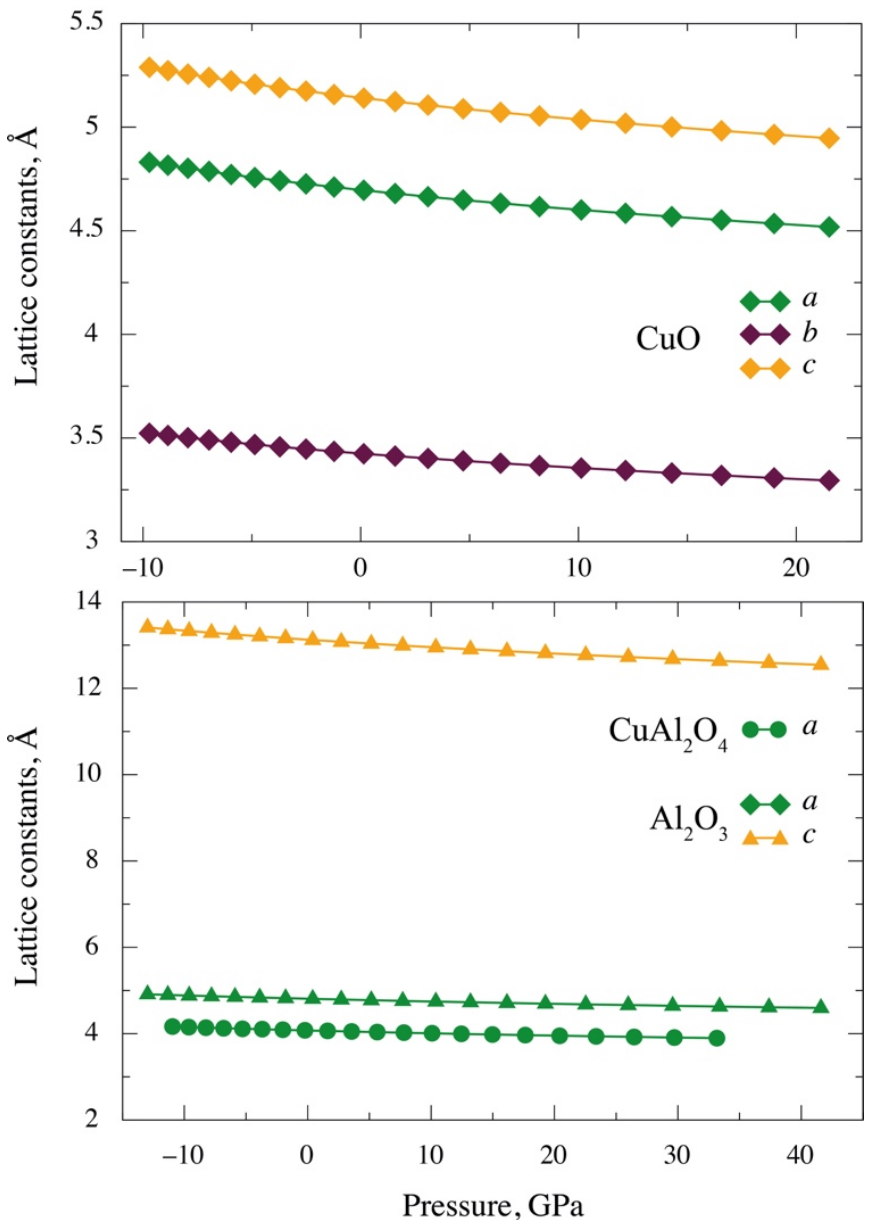

Figure 5. Variation of lattice parameters with pressure in $\mathrm{CuAl}_{2} \mathrm{O}_{4}$, $\mathrm{CuO}$, and $\mathrm{Al}_{2} \mathrm{O}_{3}$ as obtained in the DFT $+\mathrm{U}$ calculations

The compressibility of long apical $\mathrm{Cu}-\mathrm{O}$ bonds is much larger than others (which is rather natural) and this explains overall (relatively) large compressibility of $\mathrm{CuO}$. We find at pressure $8 \mathrm{GPa}$ that decrease of $\mathrm{Cu}-\mathrm{O}$ bond length is only $\sim 0.031$ in $\mathrm{CuAl}_{2} \mathrm{O}_{4}$, while the longest bond in $\mathrm{CuO}$ changes much larger, on $\sim 0.072 \AA$ (two others decrease on $0.030 \AA$ and $0.026 \AA$ ) in the same pressure range, see figure 5 .

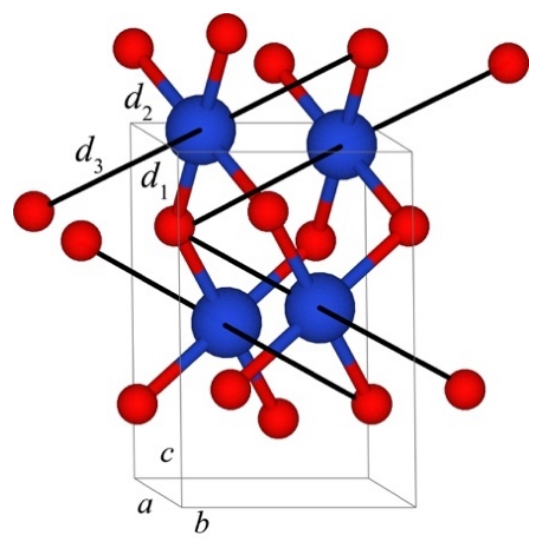

Figure 6. Crystal structure of $\mathrm{CuO}$. The blue spheres are $\mathrm{Cu}$ ions, surrounded by highly distorted oxygen (the red spheres) octahedra.

The second very important factor is the electronic correlations. We found that decrease of Hubbard $U$ on $1 \mathrm{eV}$ suppresses $P_{c}$ down to $\sim 4 \mathrm{GPa}$, so that the optimal $U$ is $\sim 8.5$ $\mathrm{eV}$. Detailed analysis shows that with decrease of $U$ nearly does not change $a, b$, and $d$ parameters in (1), but decreases $c$ coeficient for $\mathrm{CuO}$ stronger than for $\mathrm{CuAl}_{2} \mathrm{O}_{4}$ (for $U=8 \mathrm{eV}$ $c_{\mathrm{CuO}}=-7.991 \mathrm{eV}$, while $c_{\text {CuAl2O}}=-45.779 \mathrm{eV}$ ). Thus, we see that correlation effects stabilize $\mathrm{CuAl}_{2} \mathrm{O}_{4}$ under pressure. This is because of weaker hybridization of $\mathrm{Cu} 3 d$ states with $\mathrm{O} 2 \mathrm{p}$ states in tetrahedral geometry of $\mathrm{CuAl}_{2} \mathrm{O}_{4}$.

Of course there are also other factors, which affect decomposition of $\mathrm{CuAl}_{2} \mathrm{O}_{4}$ under pressure. Corrund $\left(\alpha-\mathrm{Al}_{2} \mathrm{O}_{3}\right)$ is a rather stable structure: constant coeficient $a$ for $\mathrm{Al}_{2} \mathrm{O}_{3}$ is very low and this also works for stabilization of $\mathrm{CuO}$ and $\mathrm{Al}_{2} \mathrm{O}_{3}$ mixture. One might expect that the close packed corrundum structure is clearly more favourable than cubic packing of oxygen atoms in spinels, if we apply pressure, and a rather high temperature in our experiment also facilites the decomposition.

It has to be also mentioned that present results rely on the crystal structure with the idealized atomic order $-\mathrm{Cu}$ ions occupy tetrehedral sites, while $\mathrm{Al}$ ions are octahedral. In real $\mathrm{CuAl}_{2} \mathrm{O}_{4}$ there is a certain degree of disorder between $\mathrm{Cu}$ and $\mathrm{Al}$ and this must be taken into account in further studies.

\section{Conclusions}

To sum up the stability of $\mathrm{CuAl}_{2} \mathrm{O}_{4}$ spinel under high pressure has been investigated in the present paper experimentally and theoretically. Our ex-situ X-ray powder diffraction study showed that this material decomposes at pressure of $6 \mathrm{GPa}$ above about $1070 \mathrm{~K}$ onto the final mixture of $\mathrm{CuO}$ and $\mathrm{Al}_{2} \mathrm{O}_{3}$. The DFT $+\mathrm{U}+\mathrm{SOC}$ calculations generally support this finding with critical pressure of $\sim 8 \mathrm{GPa}$ for zero temperature and demonstrate that one of the important factors, which results in decomposition, is a compressibility of $\mathrm{CuO}$. It is also shown that electronic correlations work in opposite direction additionally stabilizing $\mathrm{CuO}$ under pressure. 


\section{Acknowledgements}

S.V.S. is grateful to I. Leonov for discussion of structural stability of normal and inverse spinels.

Theoretical calculations were supported by the Russian Science Foundation via program RSF 20-62-46047.

A.A.B. was partly supported by JSPS KAKENHI Grant Number JP20H05276, a research grant (40-37) from Nippon Sheet Glass Foundation for Materials Science and Engineering, and Innovative Science and Technology Initiative for Security (Grant Number JPJ004596) from Acquisition, Technology, and Logistics Agency (ATLA), Japan.

We also thank 02.A03.21.0006 project of Russian Ministry of Education.

\section{References}

[1] Giovannetti G, Stroppa A, Picozzi S, Baldomir D, Pardo V, Blanco-Canosa S, Rivadulla F, Jodlauk S, Niermann D, Rohrkamp J, Lorenz T, Streltsov S, Khomskii D I and Hemberger J 2011 Phys. Rev. B 83, 060402(R)

[2] Yamasaki Y, Miyasaka S, Kaneko Y, He J-P, Arima T and Tokura Y 2006 Phys. Rev. Lett. 96, 207204

[3] Singh K, Maignan A, Simon C and Martin C 2011 Appl. Phys. Lett. 99172903

[4] Eremin M V 2019 JETP Letters 109249

[5] Senn M S, Wright J P and Attfield J P 2012 Nature 481173

[6] Radaelli P 2005 New Journal of Physics 753

[7] Schmidt M, Ratcliff W, Radaelli P G, Refson K, Harrison N M and Cheong S W 2004 Phys. Rev. Lett. 9256402

[8] Horibe Y, Shingu M, Kurushima K, Ishibashi H, Ikeda N, Kato K, Motome Y, Furukawa N, Mori S and Katsufuji T 2006 Phys. Rev. Lett. 96086406

[9] Khomskii D I and Mizokawa T 2005 Phys. Rev. Lett. 94156402

[10] Nirmala R, Jang K-H, Sim H, Cho H, Lee J, Yang N-G, Lee S, Ibberson R M, Kakurai K, Matsuda M, Cheong S-W, Gapontsev V V, Streltsov S V and Park J-G 2017 J. Phys.: Condens. Matter 29 13LT01

[11] Nikolaev S A, Solovyev I V, Ignatenko A N, Irkhin V Yu and Streltsov S V 2018 Phys. Rev. B 98201106 (R)

[12] Kim C H, Baidya S, Cho H, Gapontsev V V, Streltsov S V, Khomskii D I, Park J, Go A and Jin H 2019 Phys. Rev. B 100 161104

[13] Streltsov S V and Khomskii D I 2017 Phys.-Uspekhi 601121

[14] Streltsov S V and Khomskii D I 2020 Phys. Rev. X 10031043

[15] Khomskii D I and Streltsov S V arXiv:2006.05920

[16] Takagi H, Takayama T, Jackeli G, Khaliullin G and Nagler S E 2019 Nat. Rev. Phys. 1264

[17] Winter S M, Tsirlin A A, Daghofer M, van den Brink J, Singh Y, Gegenwart P and Valenti R 2017 J. Phys.: Cond. Matt. 29, 493002

[18] O'Neill H, James M, Dollase W A and Redfern S A T 2005 Eur. J. Miner. 17581

[19] Decker D L and Vanfleet H B 1965 Phys. Rev. 138 A129

[20] Izumi F, Ikeda T 2000 Mater. Sci. Forum 321-324 198

[21] Jacob K T and Alcock C B 1975 J. Am. Ceram. Soc. 58192
[22] Kresse G and Hafner J 1993 Phys. Rev. B 47 558,

[23] Kresse G and Joubert D 1999 Phys. Rev. B 591758

[24] Perdew J P, Burke K and Ernzerhof M 1996 Phys. Rev. Lett. 773865

[25] Liechtenstein A I, Anisimov V I and Zaanen J 1995 Phys. Rev. B 52 R5467

[26] Ehrenberg H, McAllister J A, Marshall W G and Attfield J P 1999 J. Phys.: Condens. Matter 116501

[27] Newnhan R E and de Haan Y M 1962 Zeitschrift fur Kristallographie $\mathbf{1 1 7} 235$

[28] Martin R M 2004 Electronic Structure: Basic Theory and Practical Methods (Cambridge : Cambridge University Press)

[29] Birch F, 1947 Phys. Rev. 7111 